\title{
Leptotrichia buccalis
}

National Cancer Institute

\section{Source}

National Cancer Institute. Leptotrichia buccalis. NCI Thesaurus. Code C76356.

A species of Gram-negative, anaerobic bacillus in the phylum Fusobacteria. 